\title{
The Effects of Estradiol and Estriol on Plasma Levels of Cortisol and Thyroid Hormone-Binding Globulins and on Aldosterone and Cortisol Secretion Rates in $\operatorname{Man} *$
}

\author{
Fred H. Katz and Attallah Kappas $\$$ \\ (From the Department of Medicine and the Argonne Cancer Research Hospital, $\$$ The \\ University of Chicago, Chicago, Illinois)
}

\begin{abstract}
Summary. The effects of estriol and estradiol on the plasma levels of cortisol- and thyroxine-binding globulin activity, and on the secretion rates of aldosterone and cortisol were studied in man. The metabolite estriol had no consistent or significant influence on plasma levels of the hormone-binding globulin activities; the hormone estradiol increased these binding capacities significantly, as expected. Cortisol secretion rate rose slightly after estriol but was unchanged after estradiol. Both compounds induced substantial increases in the aldosterone secretion rate of most treated subjects. The mechanism of this apparently paradoxical effect of estrogens is not clear; it is suggested that the "salt-retaining" action of estrogens is mediated in part by the rapid enhancement of aldosterone output which follows their administration in man. Balance experiments in four subjects suggest that both estradiol and estriol may induce a transient early natriuresis in man; but other mechanisms for estrogen stimulation of aldosterone secretion may be operative as well.
\end{abstract}

\section{Introduction}

Estriol is quantitatively the most important metabolite of estradiol, being derived from this hormone and related precursors such as estrone, via a chemical transformation which is not reversible in vivo (1). Its production is known to increase extraordinarily in pregnancy, reaching levels of $60 \mathrm{mg} /$ day or more during the last trimester of a

* Received for publication 15 May 1967 and in revised form 10 July 1967.

Supported in part by U. S. Public Health Service Training Grant TI AM 5445-03.

Presented in part at the Forty-seventh Annual Meeting of the Endocrine Society, New York, N. Y., 17-19 June 1965.

$¥$ Present address: The Rockefeller University Hospital, New York, N. Y. 10021.

§Operated by the University of Chicago for the United States Atomic Energy Commission.

Address request for reprints to Dr. Fred H. Katz, Department of Medicine, Loyola University Stritch School of Medicine, Hines, I1l. 60141. normal human gestation $(2,3)$. These amounts exceed daily production of this compound in the nongravid state by a factor of 1000 or more, thus raising the possibility that this steroid metabolite might contribute to certain of the physiological and chemical alterations known to accompany pregnancy, or participate in certain biological effects generally attributed to its precursor hormone, estradiol.

Recent studies from this laboratory have in fact demonstrated that estriol, like estradiol, was anabolic and significantly diminished spontaneous and certain secondary or experimentally induced hydroxyprolinurias in man (4), substantially reduced the incidence and severity of experimental immune arthritis in the rat (5), and in appropriate amounts regularly impaired liver function with respect to dye disposal in both man and the experimental animal $(6,7)$.

In the present study the effects of estriol on certain endocrine factors known to be altered dur- 
ing pregnancy were examined and compared with those effects induced by the natural hormone estradiol. The endocrine parameters chosen for study were the levels of the plasma-binding protein activities for thyroid hormone and for cortisol, and the secretory rate of aldosterone, all which are known to be elevated in late pregnancy (8-10) or during estrogen treatment (11-13). The secretory rate of cortisol was also measured during estriol and estradiol treatment and one possible mechanism of estrogen-induced hyperaldosteronism was tentatively explored.

\section{Methods}

Patients under study were housed on a metabolic ward, and, when indicated for this or concurrent investigations, were given constant diets or maintained on fixed intakes of sodium and potassium. The short control periods shown on the charts depicting the balance studies represent the last several days of a 7-10 day period on the constant diet prior to the initiation of steroid treatment. The majority of the patients studied had musculo-skeletal diseases; none had detectable renal, hepatic, or endocrine abnormalities, except as noted. Steroids were prepared as described in an earlier study (6). The steroid solvent vehicle alone was shown to be inert, with respect to the endocrine indices studied.

Analysis of urine sodium and potassium was performed by flame photometry or atomic absorption spectrometry; urine creatinine was measured by a minor modification (without heating) of the method of Bonsnes and Taussky (14). Thyroid hormone-binding globulin was measured indirectly using the triiodothyronine $\left(\mathrm{T}_{3}\right)$ resin uptake method of Sterling and Tabachnik (15), or the commercial Triosorb (Abbott Laboratories, Franklin Park, II1.) technique. Cortisol-binding globulin was estimated by fractionation of $1 \mathrm{ml}$ of plasma containing $0.1 \mu \mathrm{c}(1.6 \mu \mathrm{g})$ of cortisol-4- ${ }^{14} \mathrm{C}$ on Sephadex G 50 columns (16), a slight variation of the method of De Moor, Heirwegh, Heremans, and Declerck-Raskin (17). All plasma was heparinized and stored frozen until performance of the tests. Specific activities of urinary tetrahydrocortisol and tetrahydrocortisone (18) and "tetrahydroaldosterone" (19) after injections of radioactive cortisol and aldosterone were used to measure aldosterone and cortisol secretion rates concurrently by double isotope derivative methods as previously described (20). Routine statistical methods were utilized (21).

\section{Results}

Estrogen effects on thyroid hormone-binding globulin (TBG). 13 patients received estriol in amounts of $5-40 \mathrm{mg} /$ day for 3-10 days; 9 patients received estradiol in amounts of $5-50 \mathrm{mg} /$ day for 5-14 days. A minimum of two control samples of plasma and two samples at the end of the steroid treatment period was obtained at least 2 days apart from each patient (except for one treated for only 3 days, and studied twice before treatment and on the morning after the last injection). All samples from each subject were tested in duplicate at the same time. Estriol did not consistently or significantly alter the mean $T_{3}$ resin uptake in the treated subjects whereas all patients treated with equivalent or substantially lesser amounts of estradiol demonstrated the expected increase in the $\mathrm{T}_{3}$ binding activity of plasma (i.e., decreased $T_{3}$ resin uptake). Fig. 1 shows the difference between the estradiol and estriol effects graphically.

Estrogen effects on cortisol-binding globulin $(C B G) .12$ patients received estriol, $8-40 \mathrm{mg} /$ day for 5-10 days;'11 patients received estradiol, 5-100 mg/day for 4-16 days. Table I shows the results of treatment with these steroids on plasma CBG capacity, expressed as micrograms of cortisol capacity per $100 \mathrm{ml}$ of plasma for each patient. Fig. 2 compares these effects on CBG in each ster-

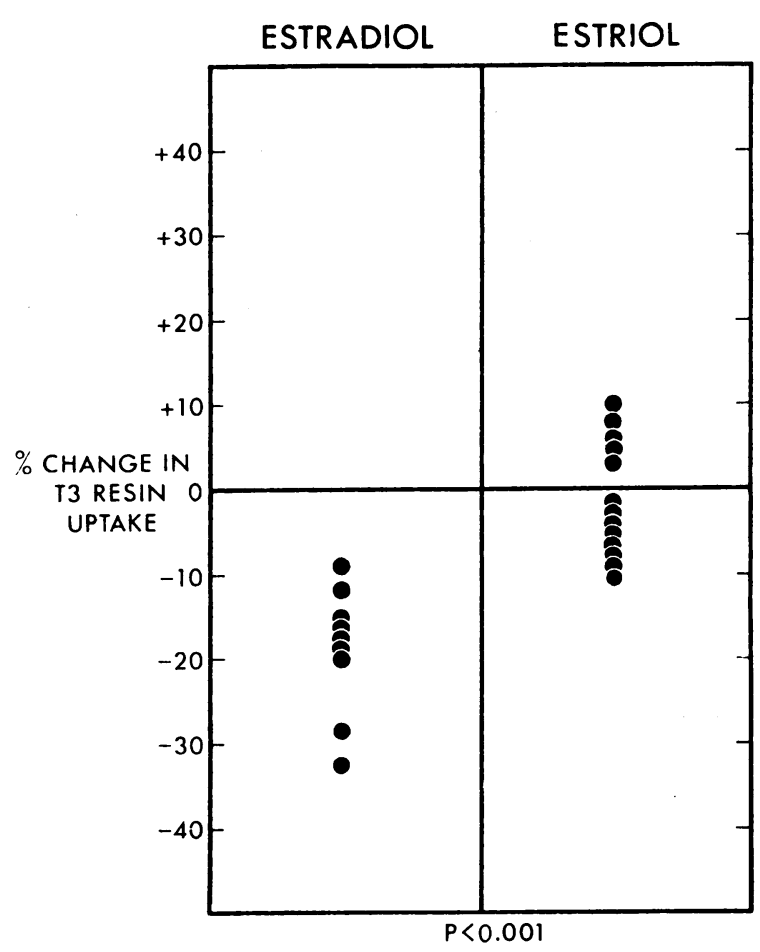

Fig. 1. Estrogen efFects ON $T_{3}$ RESIN UPtake. 13 patients received estriol, $5-40 \mathrm{mg} /$ day for 3-10 days; 9 patients received estradiol, 5-50 mg/day for 5-14 days. Patients given estradiol had a diminution of their mean $\mathrm{T}_{3}$ resin uptake while those receiving estriol had no change. 
TABLE I

Treatment schedule and $C B G$ capacity in 22 subjects

\begin{tabular}{|c|c|c|c|c|}
\hline \multirow[b]{2}{*}{ Patient } & \multirow{2}{*}{\multicolumn{2}{|c|}{ Treatment }} & \multicolumn{2}{|c|}{$\begin{array}{c}\text { CBG cortisol } \\
\text { capacity }\end{array}$} \\
\hline & & & $\begin{array}{l}\text { Con- } \\
\text { trol }\end{array}$ & $\begin{array}{c}\text { Estro- } \\
\text { gen }\end{array}$ \\
\hline & & $m g /$ day $\times$ days & $\begin{array}{r}\mu g / 1 \\
p l a\end{array}$ & $\begin{array}{l}00 \mathrm{ml} \\
\mathrm{sma}\end{array}$ \\
\hline $\begin{array}{l}\text { E.G. } \\
\text { A.R. } \\
\text { J.Z. } \\
\text { E.O. } \\
\text { J.W. } \\
\text { R.A. } \\
\text { J.F. } \\
\text { E.W.W. } \\
\text { L.W. } \\
\text { S.B. } \\
\text { M.H. } \\
\text { L.M. } \\
\text { M.M. } \\
\text { R.B. } \\
\text { E.M. } \\
\text { E.C. } \\
\text { E.K. } \\
\text { A.P. } \\
\text { J.F. } \\
\text { E.W. } \\
\text { L.S. } \\
\text { M.P. }\end{array}$ & 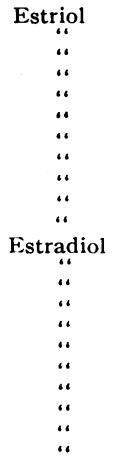 & $\begin{array}{rrr}8 & \times & 6 \\
10 & \times & 7 \\
10 & \times & 10 \\
20 & \times & 5 \\
20 & \times & 6 \\
20 & \times & 7 \\
40 & \times & 7 \\
40 & \times & 7 \\
40 & \times & 8 \\
40 & \times & 10 \\
40 & \times 10 \\
5 & \times & 6 \\
5 & \times & 7 \\
5 & \times & 10 \\
7.5 & \times & 12 \\
10 & \times & 8 \\
10 & \times & 8 \\
20 & \times & 4 \\
20 & \times & 7 \\
20 & \times & 7 \\
50 & \times & 4 \\
100 & \times 16\end{array}$ & $\begin{array}{l}27 \\
28 \\
22 \\
22 \\
23 \\
25 \\
29 \\
31 \\
29 \\
31 \\
27 \\
29 \\
19 \\
28 \\
24 \\
35 \\
31 \\
28 \\
29 \\
31 \\
25 \\
26\end{array}$ & $\begin{array}{l}21 \\
31 \\
25 \\
27 \\
23 \\
25 \\
23 \\
28 \\
32 \\
34 \\
31 \\
40 \\
37 \\
48 \\
52 \\
49 \\
50 \\
47 \\
49 \\
59 \\
46 \\
58\end{array}$ \\
\hline
\end{tabular}

oid-treated group with the range of $\mathrm{CBG}$ values observed in the same patients during a control period. Estriol administration did not significantly influence plasma CBG capacity, even when injected in the large amounts which are produced during late pregnancy; estradiol, as expected, produced consistent and striking increases in plasma

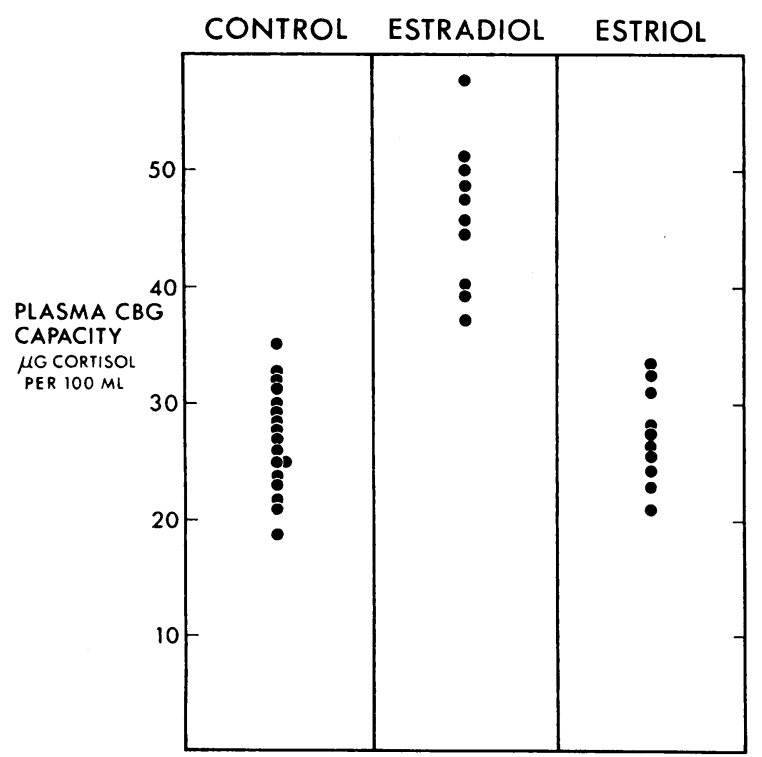

Fig. 2. Estrogen EFFECTS ON CORTISOL-BINDING GLOBULIN $(C B G)$. Subjects receiving estradiol had an increase in CBG capacity while those given estriol had no change.
CBG capacity. It is of interest that $5 \mathrm{mg}$ of this hormone was able to evoke practically as much of an increase in plasma CBG capacity as was $50-100$ mg (Table II), suggesting that the amount of this hormone excreted in pregnancy (which may exceed $5 \mathrm{mg} /$ day) probably already provides the maximal estrogenic stimulus for CBG production. Evidence that $\mathrm{CBG}$ production is actually increased after estrogen has been reported by others (22).

Estrogen effects on the secretion rate of cortisol $(C S R)$. The CSR was studied before and after steroid treatment in 12 subjects, 7 of whom received estriol $10-40 \mathrm{mg} /$ day for 5-10 days, and 5 of whom received estradiol 5-20 mg/day for 3-10 days (Table II). Estradiol did not consistently or significantly alter the CSR in either direction;

TABLE II

Treatment schedule and cortisol secretion rate in 12 subjects

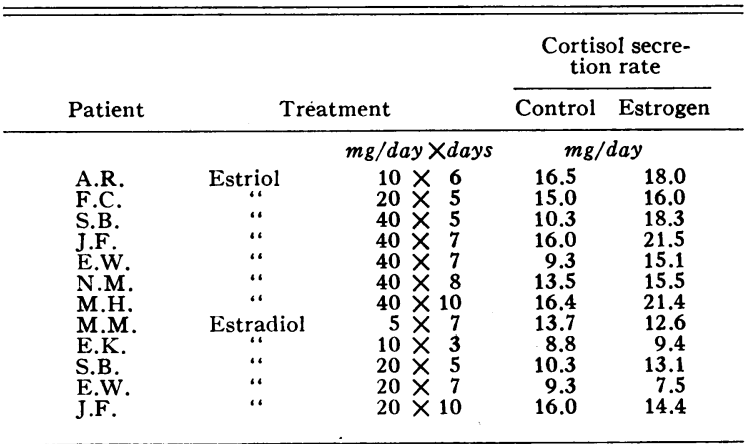

it is of interest that the CSR in none of the estrioltreated subjects decreased and that the increases noted in two subjects during steroid treatment (S.B. and E.W.) exceed 50\%. The mean CSR increased only by $4.1 \mathrm{mg} /$ day after estriol, although this increase was highly significant $(P<$ 0.001 ). However, the CSR values in all periods remained within the normal range.

Estrogen effects on the secretory rate of aldosterone $(A S R)$. The ASR was studied before and after steroid treatment in 19 subjects, 11 of whom received estriol $10-40 \mathrm{mg} /$ day for 5-11 days, and 8 of whom received estradiol $5-40 \mathrm{mg} /$ day for 3-10 days. In six subjects the ASR was determined twice during the control period; and in three subjects two or three times during the period of steroid treatment. The upper limit of nor$\mathrm{mal}$ for the ASR on a diet containing $120 \mathrm{mEq}$ of 
TABLE III

Treatment schedule and aldosterone secretion rate in 19 subjects

\begin{tabular}{|c|c|c|c|c|c|}
\hline \multirow[b]{2}{*}{ Patient } & & & \multicolumn{3}{|c|}{ Aldosterone secretion rate } \\
\hline & \multicolumn{2}{|c|}{ Treatment } & Control & Estrogen & $\begin{array}{c}\% \text { Change } \\
\text { with } \\
\text { estrogen }\end{array}$ \\
\hline & & $m g /$ day $\times$ days & & & \\
\hline M.T. & Estriol & $10 \times 10$ & 260,271 & 250 & - \\
\hline F.C. & " & $20 \times 5$ & 90 & 262 & +326 \\
\hline P.D. & “ & $20 \times 5$ & 317,346 & 260 & -23 \\
\hline A.R. & “ & $20 \times 7$ & 150 & 165 & - \\
\hline S.B. & “ & $40 \times 5$ & 70 & 145 & +107 \\
\hline A.P. & “ & $40 \times 6$ & 152 & 380 & +150 \\
\hline J.F. & “ & $40 \times 7$ & 179 & 488 & +173 \\
\hline N.M. & “ & $40 \times 8$ & 67 & 194 & +190 \\
\hline J.N. & “ & $40 \times 9$ & 194,189 & 141,111 & -32 \\
\hline M.H. & “ & $40 \times 10$ & 90 & 900 & +900 \\
\hline V.C. & “ & $40 \times 11$ & 630,438 & 2478 & +383 \\
\hline E.M. & Estradiol & $5 \times 7$ & 87 & 145 & +67 \\
\hline E.K. & “ & $10 \times 3$ & 433 & 617 & +42 \\
\hline S.M. & “ & $10 \times 10$ & 360,364 & 547 & +51 \\
\hline S.B. & “ & $20 \times 5$ & 70 & 177 & +153 \\
\hline K.R. & “ & $20 \times 6$ & 262,246 & 262,246 & - \\
\hline V.M. & “ & $20 \times 7$ & 90,90 & $150,235,190$ & +172 \\
\hline J.F. & “" & $20 \times 10$ & 179 & 189 & - \\
\hline R.G. & “ & $40 \times 8$ & 432,415 & 2300 & +445 \\
\hline
\end{tabular}

sodium in this laboratory is in the range of 200 $\mu \mathrm{g} / 24 \mathrm{hr}$. The results of the treatment on the ASR in the 19 subjects are shown in Table III. One patient in this series (E.K.) was being investigated for the presence of an aldosterone-producing tumor. S.M. had primary aldosteronism with depressed plasma renin activity due to bilateral nodular adrenocortical hyperplasia. One patient had hyperparathyroidism due to metastatic parathyroid cancer (J.F.). K.R. was a 54 yr old man with active acromegaly ; four subjects (M.T., P.D., V.C., R.G.) were on $20 \mathrm{mEq} /$ day sodium diets and subject V.C. had severe congestive heart failure. A.R. and V.M. were men and F.C., S.B., and A.P. had undergone hysterectomy.

The administration of estriol increased the ASR significantly (in excess of $20 \%$ ) in 7 out of 11 patients; these increases ranged from approximately 100 to $900 \%$ above control levels and occurred within the shortest time period studied ( 5 days) after initiation of steroid treatment. The least amount of estriol which appeared to be effective in increasing ASR was about $20 \mathrm{mg}$ /day (one subject out of three responded); while amounts of estriol in the higher ranges of those produced in pregnancy $(40 \mathrm{mg} /$ day) induced consistent and pronounced elevation in the ASR in all but one subject (J.N.). The administration of $40 \mathrm{mg}$ /day of estriol for 6 days to an adrenalectomized subject, maintained on cortisol, did not lead to the urinary excretion of metabolites behaving chromatographically like tetrahydroaldosterone, thus excluding the possibility of artifact in the ASR determination after estriol treatment.

Estradiol treatment resulted in an increase ranging from about 40 to $450 \%$ in the ASR, in six of the eight patients studied. The effect could be observed with as little as $5 \mathrm{mg}$ /day (subject E.M.) and was apparent at higher doses as quickly as 2 days after injection of the steroid (subject V.M.). It is of interest that the patients with proven and suspected primary aldosteronism (S.M. and E.K.), and subject R.G. (who was on a 20 $\mathrm{mEq} /$ day sodium diet) responded to estradiol with significant increases in ASR; the patient with hyperparathyroidism, shown to respond to estriol, did not increase her ASR on estradiol treatment. The possibility that the estradiol effect on the ASR is mediated in part through conversion to its active metabolite estriol cannot be excluded; the converse is not possible, however, since the transformation estriol $\rightarrow$ estradiol does not occur in vivo (1). The acromegalic subject (K.R.) also did not increase his ASR during estradiol administration.

Urinary excretion of sodium and potassium after estradiol and estriol treatment. The acute effects of these steroids on the urinary excretion of sodium and potassium were studied in four patients, in a tentative exploration of the possible 


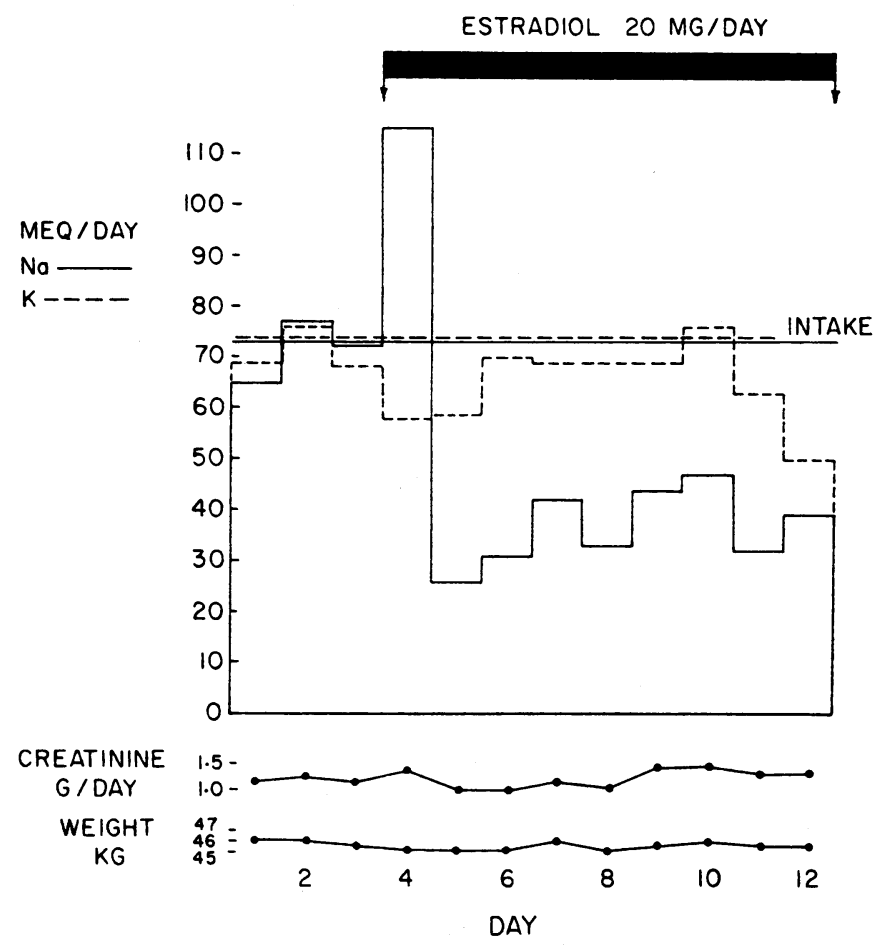

Fig. 3. URINARY EXCRETION OF SODIUM AND POTASSIUM. Urinary sodium loss was seen on the 1st day of estradiol administration.

ways in which estrogens might evoke increases in ASR in man. The effect of estradiol on the urinary excretion of these electrolytes is depicted in Figs. 3 and 4. Subject L.R. (Fig. 3), a patient with emphysema, had a marked increase in sodium excretion in the first $24 \mathrm{hr}$ after estradiol administration, followed by a prolonged period of sodium retention, due presumably to the increase in ASR induced by estradiol. There was little if any potassium retention in the first 2 days of estrogen treatment. Subject S.S. (Fig. 4) also appeared to have a transient sodium diuresis in the first 48 $\mathrm{hr}$ after estradiol administration.

The injection of estriol in two patients also appeared to be associated with a very early and transient natriuresis, as shown in Figs. 5 and 6. The effect was marked in subject V.C. (Fig. 6) who was a patient with congestive heart failure exhibiting a significantly positive sodium balance on an intake of $27 \mathrm{mEq} /$ day. Although she had been excreting less than 5 of the $27 \mathrm{mEq}$ of sodium intake per day during the control period, on days
1 and 3 of estriol treatment (the urine of the 2nd day of estriol treatment was lost) the urine sodium rose to 32 and 20 , respectively, with suggestive reciprocal changes in potassium excretion. Subsequently during the remainder of the estriol treatment period, the urinary sodium returned to its previous low levels, in keeping with the measured increase in ASR.

\section{Discussion}

Estriol is, under normal circumstances, i.e. in the nongravid state, derived from the in vivo biotransformation of estrone and estradiol in man. Studies of estrogen metabolism in pregnancy, however, have indicated that a considerable amount of estriol excreted in urine may arise from other chemical pathways (23) in which $16 \alpha$-hydroxydehydroepiandrosterone sulfate (24) and dehydroepiandrosterone sulfate (25) are important steroid precursors of estriol, and that the placenta is a major site of this biotransformation (26). 
The activity of estriol in "classical" tests of estrogenic function is strikingly less than that of estradiol and estrone (27); nevertheless, its extraordinary production rate during gestation raises the possibility that any biological properties which it might be shown to possess could contribute to certain of the physiological alterations which accompany normal human pregnancy.

The present studies show that with respect to elevation of the plasma levels of cortisol and thyroid hormone-binding globulin activity in man the metabolite estriol does not possess more than a small fraction of the activity of its ovarian precursor hormone estradiol. With due consideration of the fact that this conclusion is drawn on the basis of only short-term studies, this difference in potency between estriol and estradiol indicates that the sustained increase in CBG and TBG during pregnancy may result primarily from biological actions of the latter hormone, or perhaps derivatives which are structurally distinct from estriol, or which undergo different pathways of metabolism in vivo. The latter is an important consideration, since one reason why estriol did not produce an increase in the level of plasma-binding protein activity in this study may relate to the markedly higher rate of renal disposal of this compound, compared with estradiol (28).

Estradiol did not consistently affect the rate of cortisol secretion in this study. As noted, two of the estriol-treated subjects increased their CSR by $50 \%$ or more during treatment with this steroid and there was a small but highly significant increase in the mean CSR of the entire estriol-

S.S. $\$ 60$ RHEUM. ARTHR.

ESTRADIOL 20 MG/DAY
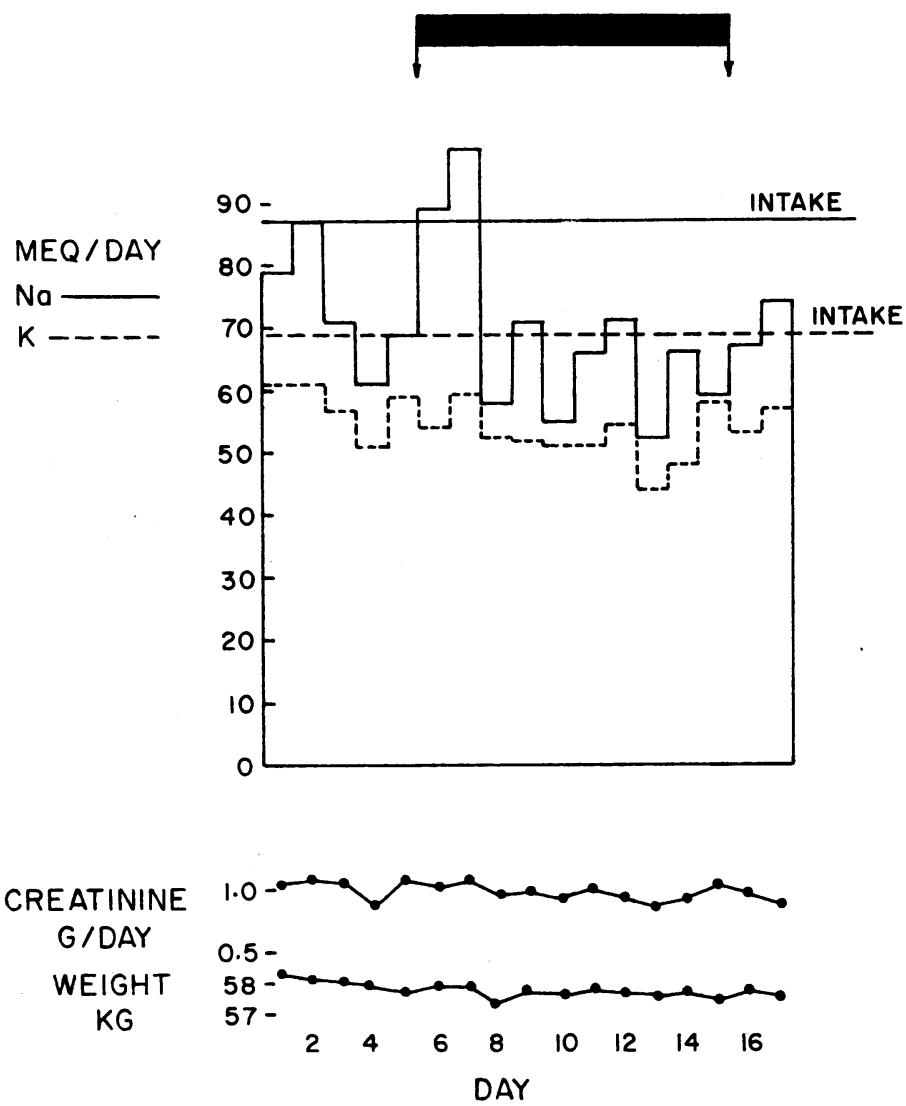

Fig. 4. URINARY EXCRetion of SOdIUM AND POTASSIUM. This subject had excretion of sodium greater than intake on the first 2 days of estradiol. 


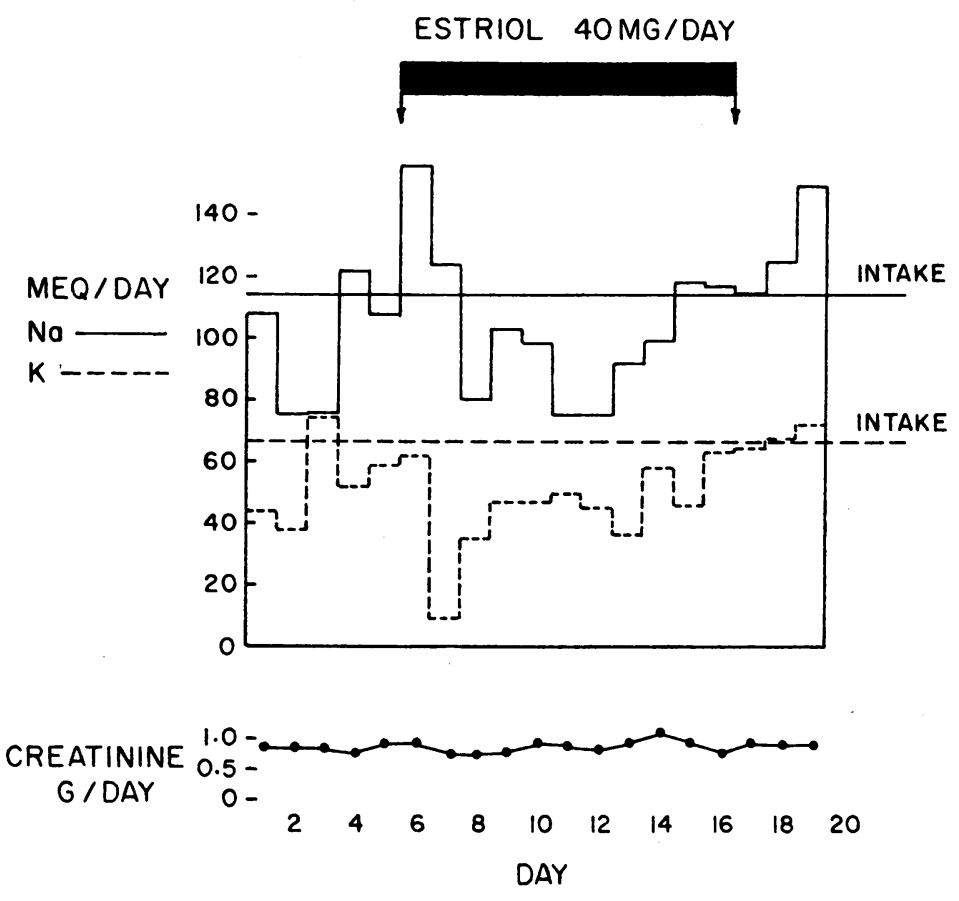

Fig. 5. Urinary excretion of Sodium and potassium. Estriol injections resulted in increased sodium excretion for 1 day followed by transient sodium retention.

treated group. Since both subjects with marked increases in CSR after estriol had a low CSR during the control period, it is conceivable that estriol treatment facilitated, or possibly coincided with, a spontaneous increase of adrenal activity in these otherwise chronically ill patients. However, this did not occur in the two estradiol-treated subjects with low control rates of cortisol secretion; in any case, the CSR did not exceed the normal range in any subject despite relatively intense, shortterm, estrogen treatment. The results are consistent with other observations on the CSR after the administration of synthetic estrogens $(29,13)$.

The most noteworthy findings in this study relate to the ability of estradiol and estriol to increase, sometimes to strikingly high levels, the rate of secretion of aldosterone in man. The effect could be demonstrated at low or high levels of salt intake (high and low base line ASR control values, respectively) and in at least one patient with primary aldosteronism as well. The stimulatory action of estriol and estradiol on the ASR is of special relevance to the situation in pregnancy since the ASR is known to increase substantially at this time.

The mechanism of the increased aldosterone production which occurs during pregnancy is not clearly understood. An important stimulant to the ASR at this time is the large amount of progesterone which is produced during gestation. This steroid has been shown to competitively inhibit aldosterone action at the renal tubular level (30), an effect which, as would be expected, results in a compensatory increase in aldosterone secretion (31).

It is clear from the present study that the striking increase in estradiol and estriol production which occurs in pregnancy may also contribute to the elevated ASR which characterizes the gravid state. The mechanism(s) of this apparently paradoxical effect is not clear although it could be explained if it could be shown that these steroids, like progesterone, were natriuretic substances. The preliminary observations reported here suggest this possibility although their tentative nature is emphasized. Layne and associates (13), who 
also demonstrated increased aldosterone secretion as a result of treatment with synthetic estrogens, suggested that these hormones are sodium-retaining substances, citing the detailed study of Preedy and Aitken (32). The latter report, however, shows a small transient net average sodium chloride loss on day 1 in the estrogen-treated group, although data for individual subjects are not given. The patients reported here (Figs. 3-6) also had a transient negative sodium balance in the initial period of estradiol or estriol treatment. This was generally followed by sustained sodium retention, and in one subject (J.N., Fig. 5) by a clear "escape" phenomenon like that seen in the Preedy and Aitken study (32) and similar to that which is observed when aldosterone is administered to normal subjects (33). The results strongly suggest that the apparent "salt-retaining" activity of these estrogens may in fact be attributed to the increased aldosterone secretion which they stimulate. Lack of consistent and marked reciprocal changes in potassium balance are not at all unusual, even when large amounts of aldosterone are administered (33).

If a transient natriuretic response consistently follows estrogen administration, the resultant stimulation of aldosterone secretion could ensue via stimulation of renal renin production. Indeed plasma renin activity is known to be elevated in human gestation (34) and has recently been found to increase after estrogen administration (35).

In addition to its usual renal source, however, the increased plasma renin during pregnancy may be largely derived from uterine stores (36). The enzyme can be found in amniotic fluid (37) and will form angiotensin II (38), but apparently does not respond to the same physiologic stimuli, i.e., salt loading and hypervolemia, that suppress renal renin production $(39,40)$. This could provide another possible sustained stimulus to aldosterone production in pregnancy.

It is of interest that androgens, like progesterone, have also been shown to compete with aldosterone at the renal tubular level $(41,42)$. Indeed older studies by Kenyon and his coworkers (43) demonstrate a renal "escape" from testosterone-induced sodium retention which could well be mediated by aldosterone. More conclusive evidence of a similar property for estrogens would extend the spectrum of aldosterone antagonism to another

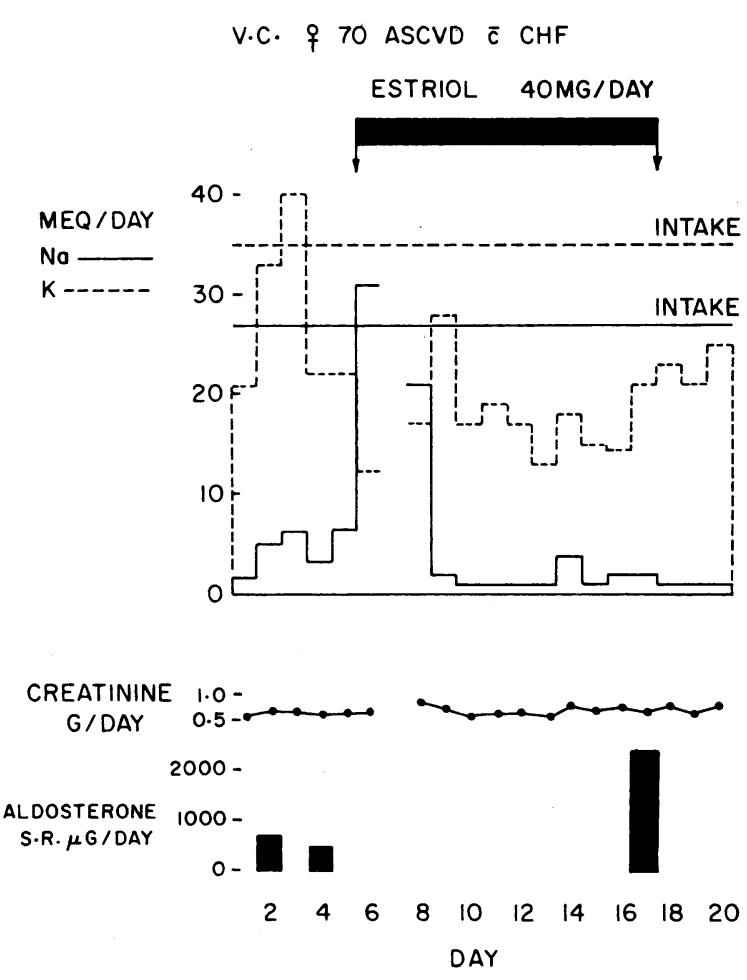

FIG. 6. URINARY EXCRETION OF SODIUM AND POTASsIUM. Estriol caused a transient increase in the very low sodium excretion in this woman with congestive heart failure. The aldosterone secretion rate rose from its already elevated levels of 630 and 438 to $2478 \mu \mathrm{g} /$ day.

class of natural hormones and one which, like progesterone, would have particular relevance to the alterations in ASR seen in pregnant women.

Mechanisms other than natriuresis for estrogen stimulation of aldosterone secretion are of course entirely possible and may for example include direct actions on the adrenal cortex, direct stimulation of renal renin production (and of uterine renin production as well in pregnancy), and alterations in the metabolism of relevant substances such as renin, renin substrate (44), angiotensin, progesterone, etc. Whatever this mechanism(s) proves to be, it is likely that this class of steroids, and particularly estriol, plays a significant role among the factors that evoke and sustain the striking hyperaldosteronism which characterizes the gravid state.

\section{Acknowledgments}

Technical assistance during various phases of this study was rendered by Miss Evelyn Damgaard, Miss 
Judith Wiley, Mrs. Valentine Harrer, Miss Grace You Lin Yao, and Miss Janet Marie Cobb. Mrs. Nancy Gallagher and Miss Carmen Dominguez devised and supervised the constant diets. Mrs. Genevieve LaPinska and Mrs. Jane Kresler prepared the manuscript.

\section{References}

1. Maner, F. D., B. D. Saffan, R. A. Wiggins, J. D. Thompson, and J. R. K. Preedy. 1963. Interrelationship of estrogen concentrations in the maternal circulation, fetal circulation and maternal urine in late pregnancy. J. Clin. Endocrinol. Metab. 23: 445.

2. Fishman, J., J. B. Brown, L. Hellman, B. Zumoff, and T. F. Gallagher. 1962. Estrogen metabolism in normal and pregnant women. J. Biol. Chem. 237 : 1489.

3. Yousem, H. L., and D. Strummer. 1964. Simple gas chromatographic method for estimation of urinary estriol in pregnant women. Am. J. Obstet. Gynecol. 88: 375.

4. Katz, F. H., and A. Kappas. 1965. The effect of natural estrogens on hydroxyproline excretion in man. J. Clin. Invest. 44: 1063. (Abstr.)

5. Mueller, M. N., and A. Kappas. 1964. Estrogen pharmacology. II. Suppression of experimental immune polyarthritis. Proc. Soc. Exptl. Biol. Med. $117: 845$.

6. Mueller, M. N., and A. Kappas. 1964. Estrogen pharmacology. I. The influence of estradiol and estriol on hepatic disposal of sulfobromophthalein (BSP) in man. J. Clin. Invest. 43: 1905.

7. Gallagher, T. F., M. N. Mueller, and A. Kappas. 1965. Studies on the mechanism and structural specificity of the estrogen effect on BSP metabolism. Trans. Assoc. Am. Physicians. 78: 187.

8. Slaunwhite, W. R., and A. A. Sandberg. 1959. Transcortin: A corticosteroid-binding protein of plasma. J. Clin. Invest. $38: 384$.

9. Dowling, J. T., N. Freinkel, and S. H. Ingbar. 1956. Thyroxine-binding by sera of pregnant women. J. Clin. Endocrinol. Metab. 16: 280.

10. Watanabe, M., C. I. Meeker, M. J. Gray, E. H. Sims, and S. Solomon. 1963. Secretion rate of aldosterone in normal pregnancy. J. Clin. Invest. 42 : 1619.

11. Sandberg, A. A., and W. R. Slaunwhite. 1959. Transcortin: A corticosteroid-binding protein of plasma. II. Levels in various conditions and the effects of estrogens. J. Clin. Invest. 38: 1290.

12. Dowling, J. T., N. Freinkel, and S. H. Ingbar. 1956. Effect of diethylstilbestrol on the binding of thyroxine in serum. J. Clin. Endocrinol. Metab. 16: 1491.

13. Layne, D. S., C. J. Meyer, P. S. Vaishwanar, and G. Pincus. 1962. The secretion and metabolism of cortisol and aldosterone in normal and steroid treated women. J. Clin. Endocrinol. Metab. 22 : 107.

14. Bonsnes, R. W., and H. H. Taussky. 1945. On the colorimetric determination for creatinine by the Jaffe reaction. J. Biol. Chem. 158: 581.

15. Sterling, K., and M. Tabachnik. 1961. Resin uptake of $\mathrm{I}^{131}$-triiodothyronine as a test of thyroid function. J. Clin. Endocrinol. Metab. $21: 456$.

16. Seal, U. S., and R. P. Doe. 1963. Corticosteroidbinding globulin: Species distribution and smallscale purification. Endocrinology. 73: 371.

17. De Moor, P., K. Heirwegh, J. F. Heremans, and M. Declerk-Raskin. 1962. Protein binding of corticoids studied by gel filtration. J. Clin. Invest. $41: 816$.

18. Peterson, R. E. 1959. The miscible pool and turnover rate of adrenocortical steroids in man. $R e$ cent Progr. Hormone Res. 15 : 231.

19. Ulick, S., J. H. Laragh, S. Lieberman, and R. F. Loeb. 1958. Isolation of a urinary metabolite of aldosterone and its use to measure the rate of secretion of aldosterone by the adrenal cortex of man. Trans. Assoc. Am. Physicians. $71: 225$.

20. Katz, F. H. 1964. Adrenal function during bed rest. Aerospace Med. $35: 849$.

21. Snedecor, G. W. 1956. Statistical Methods Applied to Experiments in Agriculture and Biology. Iowa State College Press, Ames. 5th edition.

22. Sandberg, A. A., M. Woodruff, H. Rosenthal, S. Nienhouse, and W. R. Slaunwhite. 1964. Transcortin: A corticosteroid-binding protein of plasma. VII. Half-life in normal and estrogen-treated subjects. J. Clin. Invest. 43 : 461.

23. Gurpide, E., M. Angers, R. L. Vande Wiele, and S. Lieberman. 1962. Determination of secretory rates of estrogens in pregnant and nonpregnant women from the specific activities of urinary metabolites. J. Clin. Endocrinol. Metab. 22 : 935.

24. Easterling, W. E., H. H. Simmer, W. J. Dignam, M. V. Frankland, and F. Naftolin. 1966. Neutral $\mathrm{C}_{10}$-steroids and steroid sulfates in human pregnancy: II. Dehydroepiandrosterone sulfate, $16 \alpha$-hydroxydehydroepiandrosterone, and 16 $\alpha$-hydroxydehydroepiandrosterone sulfate in maternal and fetal blood of pregnancies with anencephalic and normal fetuses. Steroids. 8: 157.

25. MacDonald, P. C., and P. K. Siiteri. 1965. Origin of estrogen in women pregnant with an anencephalic fetus. J. Clin. Invest. 44: 465.

26. Bolte, E., S. Mancuso, G. Eriksson, N. Wiquist, and E. Diczfalusy. 1964. Studies on the aromatisation of neutral steroids in pregnant women. I. Aromatisation of C-19 steroids by placentas perfused in situ. Acta Endocrinol. 45: 535.

27. Miyake, T. 1961. Inhibitory effects of various steroids on gonadotropin hypersecretion in parabiotic mice. Endocrinology. 69 : 534.

28. Brown, C. H., B. D. Saffan, C. M. Howard, and J. R. K. Preedy. 1964. The renal clearance of 
endogenous estrogens in late pregnancy. J. Clin. Invest. 43 : 295.

29. Peterson, R. E., G. Nokes, P. S. Chen, and R. L. Black. 1960. Estrogens and adrenocortical function in man. J. Clin. Endocrinol. Metab. 20: 495.

30. Landau, R. L., and K. Lugibihl. 1958. Inhibition of the sodium-retaining influence of aldosterone by progesterone. J. Clin. Endocrinol. Metab. 18: 1237.

31. Laidlaw, J. C., J. L. Ruse, and A. G. Gornall. 1962. The influence of estrogen and progesterone on aldosterone excretion. J. Clin. Endocrinol. Metab. $22: 161$.

32. Preedy, J. R. K., and E. H. Aitken. 1956. The effect of estrogen on water and electrolyte metabolism. I. The normal. J. Clin. Invest. $35: 423$.

33. August, J. T., D. H. Nelson, and G. W. Thorn. 1958. Response of normal subjects to large amounts of aldosterone. J. Clin. Invest. 37: 1549.

34. Brown, J. J., D. L. Davies, P. B. Doak, A. F. Lever, and J. I. S. Robertson. 1963. Plasma renin in normal pregnancy. Lancet. 2: 900.

35. Crane, M. G., J. Heitsch, J. J. Harris, and V. J. Johns. 1966. Effect of ethinyl estradiol (estinyl) on plasma renin activity. J. Clin. Endocrinol. Metab. 26: 1403.

36. Ferris, T. F., P. Gorden, and P. J. Mulrow. 1967. Rabbit uterus as a source of renin. Am.J. Physiol. 212: 698.
37. Brown, J. J., D. L. Davies, P. B. Doak, A. F. Lever, J. I. S. Robertson, and M. Tree. 1964. The presence of renin in human amniotic fluid. Lancet. 2: 64 .

38. Gross, F., G. Schaechtelin, M. Ziegler, and M. Berger. 1964. A renin-like substance in the placenta and uterus of the rabbit. Lancet. 1: 914.

39. Brown, J. J., D. L. Davies, P. B. Doak, A. F. Lever, and J. I. S. Robertson. 1966. Serial estimation of plasma renin concentration during pregnancy and after parturition. J. Endocrinol. $35: 373$.

40. Gorden, P., T. F. Ferris, and P. J. Mulrow. 1967. Rabbit uterus as a possible site of renin synthesis. Am. J. Physiol. 212 : 703.

41. Kagawa, C. M., and R. S: Jacobs, Jr. 1959. Action of testosterone in blocking urinary electrolyte effects of desoxycorticosterone. Proc. Soc. Exptl. Biol. Med. 102 : 521.

42. Williamson, H. E. 1965. Natriuretic action of certain adrenocortical androgens. Steroids. 6: 365.

43. Kenyon, A. T., K. Knowlton, I. Sandiford, F. C. Koch, and G. Lotwin. 1940. A comparative study of the metabolic effects of testosterone propionate in normal men and women and in eunuchoidism. Endocrinology. 26: 26.

44. Helmer, O. M., and R. S. Griffith. 1952. The effect of the administration of estrogens on the reninsubstrate (hypertensinogen) content of rat plasma. Endocrinology. $51: 421$. 